\title{
A natureza jurídica do direito a ser esquecido e o ordenamento jurídico espanhol
}

\author{
The legal nature of the right to be forgotten and the spanish legal framework
}

\author{
Pedro Miguel dos Santos Bogas da Fonseca*
}

\section{Resumo}

\begin{abstract}
Brevemente, e por imposição do Regulamento (UE) 2016/679, do Parlamento Europeu e do Conselho, de 27 de abril de 2016, entrará em vigor, para todos os Estados-membros da União Europeia, uma nova regulação em matéria de proteção de dados pessoais, sendo que um dos seus aspetos mais inovadores é a inclusão do direito ao esquecimento. No entanto, tem-se discutido qual a natureza jurídica desse direito, sendo que as posturas defendidas se podem resumir a três: o direito ao esquecimento fundamentado no tradicional direito à intimidade; o direito ao esquecimento como consequência necessária e indissociável do direito à proteção de dados pessoais; o direito ao esquecimento como expressão da dignidade da pessoa e do livre desenvolvimento da personalidade. O presente artigo pretende, portanto, realizar uma breve análise das três principais teorias relativas à fundamentação ou natureza desse direito, com especial enfoque na jurisprudência e doutrina espanhola, finalizando com a defesa da nossa posição e os argumentos que a justificam.
\end{abstract}

Palavras-chave: Direito ao esquecimento. Natureza jurídica. Principais teorias. Proteção de dados. Intimidade. Dignidade.

\section{Abstract}

\begin{abstract}
A new regulation on the protection of personal data will come into force for all the Member States of the European Union by Regulation (EU) 2016/679 of the European Parliament and of the Council of 27 April 2016, one of its most innovative aspects being the inclusion of the right to forgetfulness. However, it has been discussed the legal nature of this right, and the positions held can be summarized as three: the right to forget based on the traditional right to intimacy, the right to forgetf as a necessary and inseparable consequence of the right to the protection of personal data; the right to forget as an expression of the dignity of the person and the free development of the personality. The present article intends to make a brief analysis of the three main theories regarding the foundation or nature of this right with a special focus on Spanish jurisprudence and doctrine, ending with the defense of our position, presenting the arguments that justify it.
\end{abstract}

Keywords: Right to be forgetten. Legal nature. Main theories. Data protection. Intimacy. Dignity.

\section{Introdução}

A 25 de maio de 2018, todos os Estados-membros da União Europeia contarão com um novo instrumento jurídico, de obrigatória adoção e cumprimento, em matéria de proteção de dados pessoais. Referimo-nos ao Regulamento (UE) 2016/679 do Parlamento Europeu e do Conselho, de 27 de abril de 2016, relativo à proteção das pessoas singulares no que diz respeito ao tratamento de dados pessoais e à livre circulação desses dados, e que revoga a Diretiva 95/46/CE (Regulamento Geral sobre a Proteção de Dados). Esta nova normativa vem, portanto, proporcionar aos distintos Ordenamentos Jurídicos 
um marco comum para a defesa de um direito tão fundamental como é o direito à proteção dos dados pessoais, reconhecendo a todos os cidadãos um conjunto de faculdades que lhes permitem a eficaz defesa e completo respeito por essa sua prerrogativa. Uma dessas faculdades que se decidiu incluir na regulação do supracitado diploma foi o direito a ser esquecido, ou direito ao esquecimento (artigo 17 do Regulamento). ${ }^{1}$

\section{Fundamento ou natureza jurídica do direito ao esquecimento}

\subsection{As teorias em torno do fundamento do direito ao esquecimento}

Assim, como não podia ser de outra forma, pela importância que pode vir a desempenhar para a determinação do regime legal aplicável à proteção (e exercício) do direito a ser esquecido, será indispensável indicar com precisão qual a natureza jurídica ou fundamento subjacente ao mencionado direito, ou, dito de outra maneira, 1) se o direito a ser esquecido deve ser entendido como resultado dos direitos de personalidade (em concreto, os direitos consagrados no artigo 18.1 da Constituição Espanhola ${ }^{2}$ - honra, intimidade pessoal e familiar e própria imagem) ou, por outro lado, como 2) consequência do exercício dos direitos de cancelamento e de oposição, isto é, derivado do direito fundamental à proteção de dados pessoais que, em Espanha, se encontra amparado pelo artigo 18.4 da Constituição. A relevância deste passo é indiscutível, pois, a consideração do direito a ser esquecido como instrumento para a proteção de certos direitos da personalidade, ou como "ferramenta" à disposição dos interessados para cancelar ou opôr-se ao tratamento das suas informações pessoais (nos meios digitais), determinará se, por um lado, aplicar-se-á a "Ley Orgánica" 5/1992, de 29 de outubro, de Regulação do Tratamento Automatizado dos Dados de Caráter Pessoal (adiante, LORTAD), oua "Ley Orgánica" 15/1999, de 13 de dezembro,

Regula o artigo 17, sobre o "Direito ao apagamento dos dados («direito a ser esquecido»)":

"1. O titular tem o direito de obter do responsável pelo tratamento o apagamento dos seus dados pessoais, sem demora injustificada, e este tem a obrigação de apagar os dados pessoais, sem demora injustificada, quando se aplique um dos seguintes motivos:

a) Os dados pessoais deixaram de ser necessários para a finalidade que motivou a sus recolha ou tratamento;

b) O titular retira o consentimento em que se baseia o tratamento dos dados nos termos do artigo $6 .^{\circ}$, n. ${ }^{\circ} 1$, alínea a), ou do artigo $9 .^{\circ}$, n. ${ }^{\circ} 2$, alínea

a) e se não existir outro fundamento jurídico para o referido tratamento;

c) O titular opõe-se ao tratamento nos termos do artigo $21 .^{\circ}, \mathrm{n} .^{\circ} 1$, e não existem interesses legítimos prevalecentes que justifiquem o tratamento, ou o titular opõe-se ao tratamento nos termos do artigo $21 .^{\circ}, \mathrm{n} .^{\circ} 2$;

d) Os dados pessoais foram tratados ilicitamente;

e) Os dados pessoais têm de ser apagados para o cumprimento de uma obrigação jurídica decorrente do direito da União ou de um Estadomembro a que o responsável pelo tratamento esteja sujeito;

f) Os dados pessoais foram recolhidos no contexto da oferta de serviços da sociedade da informação referida no artigo $8 .^{\circ}$, n. $^{\circ} 1$.

2. Quando o responsável pelo tratamento tiver tornado públicos os dados pessoais e for obrigado a apagá-los nos termos do $n$. $^{\circ} 1$, toma as medidas que forem razoáveis, incluindo de caráter técnico, tendo em consideração a tecnologia disponível e os custos da sua aplicação, para informar os responsáveis pelo tratamento efetivo dos dados pessoais de que o titular dos dados lhes solicitou o apagamento das ligações para esses dados pessoais, bem como das cópias ou reproduções dos mesmos.

3. Os n. ${ }^{\circ} \mathrm{s} 1$ e 2 não se aplicam na medida em que o tratamento se revele necessário:

a) Ao exercício da liberdade de expressão e de informação;

b) Ao cumprimento de uma obrigação legal que exija o tratamento prevista pelo direito da União ou de um Estado-Membro a que o responsável esteja sujeito, ao exercício de funções de interesse público ou ao exercício da autoridade pública de que esteja investido o responsável pelo tratamento;

c) Por motivos de interesse público no domínio da saúde pública, nos termos do artigo $9 .^{\circ}, \mathrm{n} .{ }^{\circ} 2$, alíneas $\mathrm{h}$ ) e i), bem como do artigo $9 .^{\circ}, \mathrm{n} .{ }^{\circ} 3$;

d) Para fins de arquivo de interesse público, para fins de investigação científica ou histórica ou para fins estatísticos, nos termos do artigo $89 .{ }^{\circ}$, n. ${ }^{\circ} 1$, na medida em que o direito referido no $n .^{\circ} 1$ seja suscetível de tornar impossível ou prejudicar gravemente a obtenção dos objetivos desse tratamento; ou

e) Para efeitos de declaração, exercício ou defesa de um direito num processo judicial".

2 Diz o artigo 18 da Constituição Espanhola:

"1. Garante-se o direito à honra, à intimidade pessoal e familiar e à própria imagem.

2. O domicílio é inviolável. Nenhuma entrada ou registo se poderá realizar nele sem o consentimento do titular ou resolução judicial, salvo nos casos de flagrante delito.

3. Garante-se o segredo das comunicações e, especialmente, das postais, telegráficas e telefónicas, excepto resolução judicial.

4. A Lei limitará o uso da informática para garantir a honra e a intimidade pessoal e familiar dos cidadãos e o pleno exercício dos seus direitos". 
de Proteção de Dados de Caráter Pessoal (LOPD) e restante legislação nacional e comunitária sobre proteção de dados pessoais. ${ }^{3}$

\subsection{Uma terceira via na fundamentação do direito ao esquecimento}

Não obstante, uma terceira teoria foi defendida por Simón Castellano (2012) que, com base na sua argumentação, pretende basear a criação de um direito ex novo constitucionalmente tutelado - o direito ao esquecimento ${ }^{4}$ - na dignidade da pessoa e no livre desenvolvimento da personalidade. Para esse autor, o fato de o legislador constitucional ter previsto a dignidade da pessoa e o livre desenvolvimento da personalidade (artigo 10.1 da Constituição Espanhola) ${ }^{5}$ em um momento anterior ou introdutório à consagração dos direitos fundamentais e das liberdades públicas (artigos 15 e seguintes da Constituição Espanhola), permite intuir que "a doutrina e a jurisprudência outorgaram-lhe a força dum autêntico valor jurídico comparável aos valores superiores, logo serve de fundamento de direito, inspira o seu aperfeiçoamento e ajuda à sua interpretação". Segundo o que acabamos de referir, atendendo à própria argumentação de Simón Castellano (2012), a dignidade e o livre desenvolvimento da personalidade inspiram.

[...] os direitos fundamentais e a sua correta interpretação, garantindo-se, em todo o caso, o direito de cada pessoa a determinar livremente a sua vida -presente e futura- de maneira consciente e responsável e a obter o correspondente respeito por parte dos demais. $O$ art. 10.1 da CE reconhece a autonomia do indivíduo, a sua liberdade de atuar e decidir livremente sobre o seu projeto vital, assim como a possibilidade de alterá-lo, modificá-lo e inová-lo tantas vezes como queira, e inclusivamente, não o ter. Assim, o citado preceito recolhe um bem jurídico que a carta magna pretende tutelar (SIMÓN CASTELLANO, 2012, p. 117-118).

Por conseguinte, entende esse autor que, o direito ao esquecimento pretende estender a sua esfera de proteção a um bem jurídico que vai mais além do tradicionalmente estimado e protegido. A finalidade do direito ao esquecimento seria, então, a proteção das pessoas "frente a la difusión de todas las informaciones pasadas que les puedan afectar en el futuro, con indiferencia de si afectan o no a los derechos de la vida privada $[. . .]^{6 "}$ (SIMÓN CASTELLANO, 2012, p. 121). Em coerência com a argumentação utilizada para a defesa da sua teoria e opinião, afirma Simón Castellano (2012, p. 123) que o fato de o direito ao esquecimento não encontrar previsão explícita no texto da Constituição Espanhola não constituiria, por si só, um obstáculo ou óbice a que se procedesse à sua criação e respectivo reconhecimento, pois entende que a Constituição é de tal forma maleável e flexível (segundo as suas próprias palavras, "está abierta a

\footnotetext{
Em semelhante sentido do que acabamos de mencionar, Miers Miers (2014, p. 12) considera que "A la hora de fundar el derecho al olvido, en lugar de optar por configurarlo como derecho autónomo, existen dos alternativas: bien construirlo como proyección de ciertos derechos de la personalidad, en particular, los derechos a la intimidad o a la vida privada, en la terminología del Convenio Europeo de Derechos Humanos, y al honor; bien como proyección del derecho a la protección de datos. La primera alternativa ha sido la transitada por la doctrina y la jurisprudencia tanto en España como en varios países de nuestro entorno en relación con los medios tradicionales de comunicación, pero que también puede extenderse a las formas de divulgación en línea de la información. La segunda es la adoptada por distintas autoridades nacionales de protección de datos a la hora de aplicar la normativa en esta materia y la desarrollada por la Comisión Europea a través de la propuesta del Reglamento general de protección de datos". No entanto, e no que se refere à normativa aplicável a cada uma das alternativas, continua o referido autor afirmando que "Mientras la tutela a partir de los derechos al honor y a la intimidad es un ámbito regido por las normas nacionales (en el caso de España, art. 18.1 CE y Ley Orgánica 1/1982, de 5 de mayo, de protección civil de protección al honor, a la intimidad personal y familiar y a la propia imagen, básicamente), la protección derivada del derecho a la protección de datos es un espacio sujeto a la armonización de la normativa europea".

4 Simón Castellano (2012, p. 119-120, tradução nossa) define o direito ao esquecimento como "um direito de liberdade do cidadão, a poder escolher quando e dentro de que limites procede revelar dados e informações que formam parte da sua identidade", considerando igualmente que "nasce como um direito de autodeterminação informativa, isto é, um direito a ter controlo sobre os dados pessoais -habeas data-, a decidir quais podem ser tratados e consultados por olhos estranhos. E a autodeterminação informativa, consciente e responsável, é uma manifestação direta da integridade moral do ser humano, que frente à ingente memória digital, exige o controlo dos dados pessoais para permitir o livre desenvolvimento da vida conforme as convicções, crenças e princípios que cada um eleja".

5 Art. 10.1 CE: "A dignidade da pessoa, os direitos invioláveis que lhe são inerentes, o livre desenvolvimento da personalidade, o respeito pela lei e pelos direitos dos demais são fundamento da ordem política e da paz social”. (Tradução do autor).

6 Em um momento posterior da sua obra, Simón Castellano (2012, p. 125) defende explícita e claramente que o bem jurídico que se pretende tutelar e proteger não é outro que a "liberdade de atuar e o livre desenvolvimento do projeto vital".
} 
adaptarse a las transformaciones y cambios sociales") que admite a possibilidade ou eventualidade de originar a formulação de novos direitos - ou direitos não escritos - de base jurisprudencial. ${ }^{7}$

Assim, resume a sua posição no que se refere à criação ex novo do direito ao esquecimento, constitucionalmente consagrado e protegido, da seguinte forma:

En otras palabras, el marco constitucional contempla la posibilidad que valores generales, como son la dignidad y la libertad, inspiren el surgimiento de derechos no escritos para dar respuesta a nuevos retos derivados de los cambios y transformaciones sociales. En ese ámbito puede ubicarse el derecho al olvido, que se manifiesta en determinadas normativas -prescripción de los antecedentes penales, anonimización de las sentencias- y puede derivarse implícitamente del art. 10.1 de la CE, esto es, de la dignidad humana y del libre desarrollo de la personalidad. Este sería el fundamento jurídico del derecho al olvido, hoy más difícil de satisfacer dadas las grandes capacidades de las nuevas tecnologías que facilitan la difusión, el almacenamiento y el acceso a la información. (SIMÓN CASTELLANO, 2012, p. 124-125).

Quanto ao conteúdo desse direito ao esquecimento, defende Simón Castellano (2012, p. 127) que deverá incluir aquelas lembranças e recordações de fatos e informações passadas (como podem ser notícias ou vídeos) que podem prejudicar o futuro e o livre desenvolvimento da personalidade dos interessados afetados, independentemente de dita informação ter ou não relevância pública, ou um interesse exclusivamente privado. ${ }^{8}$ De acordo com a opinião do autor, essa situação extravasa a esfera de atuação e o âmbito tutelado pelo direito à proteção da vida privada.

Já por nós, discordamos da opinião formulada por esse autor. No entanto, e antes de passar a explicar os motivos pelos quais não concordamos com a posição adotada por Simón Castellano (2012), cabe destacar que nem a doutrina ${ }^{9}$ nem a jurisprudência (concretamente, a espanhola) conseguiram alcançar uma concetualização de dignidade da pessoa humana de uma forma totalmente satisfatória e completa. ${ }^{10}$

O Tribunal Constitucional Espanhol, em várias ocasiões, pronunciou-se sobre a matéria relativa à dignidade de forma directa ou indirecta. Assim, entre as várias sentenças pronunciadas pelo Supremo Intérprete da Constituição Espanhola, destacamos a STC 91/2000, de 30 de março que, trazendo à colação o que havia declarado em decisões anteriores, deixou patente alguns dos contornos ou características da dignidade da pessoa. Nessa sua apreciação, o Tribunal Constitucional manifestou que a dignidade há de

E até mesmo, pela adoção e sujeição a textos supranacionais que consagrem esses mesmos direitos (sem esquecer a criação de direitos por imperativos de política jurídica ou justificados nos próprios desenvolvimentos sociais e económicos que impliquem a necessidade de reconhecer esses "novos" direitos).

8 Esta afirmação vem a ser completada na página 132, aclarando que "El contenido esencial del derecho al olvido estaría integrado por la garantía individual frente a la divulgación de hechos pasados, que no responden a un interés público actual, y que pueden condicionar el libre desarrollo del proyecto vital. Más concretamente, nos referimos a informaciones contenidas en expedientes de antecedentes penales, indultos, sanciones administrativas, sanciones disciplinarias, resoluciones judiciales, concesiones de ayudas en casos de exclusión social y para recibidas, las deudas pasadas y vencidas, etc. Aunque tengan la consideración de "hechos pasados» que pueden condicionar el libre desarrollo de la personalidad, el derecho al olvido tendría que decaer, en sentido general, en caso de que los hechos comunicados se consideren de relevancia pública actual, hipótesis donde las libertades informativas prevalecerían". (SIMÓN CASTELLANO, 2012, p. 127).

9 Enériz Olaechea (2007, p. 154, tradução nossa) teve a audácia e ousadia de tentar formular uma possível definição de dignidade, algo que há que louvar. Para o mencionado autor, a dignidade será "a qualidade humana de ser digno, isto é, de ser respeitado, de ser tratado por um terceiro com respeito, sem menosprezo algum, como merecedor de proteção". Para De Esteban e para González-Trevijano (1997, p.21, tradução nossa), antes de se proceder a uma possível definição de "dignidade", será indispensável tomar em consideração três premissas básicas: em primeiro lugar, teremos de compreender que a "supremacía do ser humano no mundo significa que todos os homens, por serem pessoas, têm de ser iguais em dignidade"; a segunda premissa implica que "o homem conserva a sua dignidade até ao momento da sua morte, por cima de qualquer circunstância, tempo ou lugar"; finalmente, "ao homem não se lhe pode substrair a sua personalidade, pois concebida esta como dignidade da pessoa deve ser intocável para toda a ordem humana". Expostas e consideradas essas premissas, ambos autores avançam em um "concepto operativo y provisional de lo que se debe entender en la actualidad como dignidad de la persona y que podríamos definir como «el respeto debido a toda persona, por encima de sus circunstancias propias, y que prohíbe cualquier tratamiento que puede suponer un menoscabo en el ejercicio de sus derechos fundamentales". (DE ESTEBAN; GONZÁLEZ-TREVIJANO, 1997, p. 25).

10 Entre as várias dificuldades que impossibilitam (ou pelo menos obstaculizam) a definição de dignidade da pessoa, está o caráter relativo do conceito, abstratamente considerado. Para Von Münch, "uma dificuldade adicional resulta da circunstância de que o conceito de dignidade da pessoa em modo algum é um conceito absoluto. A mesma medida dum poder público pode violar a dignidade duma mulher, mas não a dum homem; o mesmo ato estadual pode vulneral a dignidade duma pessoa de idade, mas não a dum jovem; a mesma medida dum poder público pode transgredir a dignidade dum civil, mas não afetar a dum soldado durante um periodo de formação". (VON MÜNCH, 1982, p. 18, tradução nossa). 
ser entendida como valor espiritual e moral inerente à pessoa que, por sua vez, permanecerá inalterada, independentemente das circunstâncias ou do tempo, o que conformará um "mínimo invulnerável" que há de ser protegido pelo ordenamento jurídico. ${ }^{11}$

\subsection{Argumentação contra a terceira via}

Apesar da lógica associada à argumentação de Simón Castellano, não podemos concordar com esse autor. Deste modo, passamos a enumerar os motivos que justificam a nossa oposição a considerar o direito ao esquecimento como direito autónomo merecedor de tutela constitucional:

1) Em primeiro lugar, a dignidade da pessoa e o livre desenvolvimento da personalidade não são, à luz da ordem constitucional espanhola, direitos fundamentais.

Ainda que o artigo $10.1 \mathrm{CE}^{12}$ se encontre inserido no Título I ("De los derechos y deberes fundamentales"), entendemos que o preceito é bastante claro no que diz respeito à função da dignidade da pessoa e do livre desenvolvimento da personalidade: fundamentam a ordem política e a paz social, e servirão de justificação e de base para a consagração e proteção dos direitos fundamentais. Portanto, os direitos fundamentais tutelados pela Constituição, o modo de exercício e a sua criação obedecerão sempre a critérios e requisitos derivados diretamente da dignidade humana.

Além do mais, o artigo 53.2 da Constituição Espanhola (relativo às garantias das liberdades e direitos fundamentais) exclui do âmbito de proteção do recurso de amparo ${ }^{13}$ o art. $10.1 \mathrm{CE},{ }^{14}$ ou seja, não se poderá recorrer à figura do recurso de amparo quando a pretensão que se invoca fundamenta-se em uma conduta contrária àquilo que se prevê no art. 10.1 da Constituição. Determina o mencionado artigo 53.2 da CE que:

Qualquer cidadão poderá obter a tutela das liberdades e direitos reconhecidos no artigo 14 e a Secção Primeira do Capítulo segundo ante os Tribunais ordinários por um procedimento baseado nos principios de preferência e sumariedade e, consoante o caso, através do recurso de amparo ante o tribunal Constitucional. Este último recurso será aplicável à objeção de consciência reconhecida pelo artigo 30. (Tradução nossa).

11 É o que se retira do Fundamento Jurídico Sétimo: "Pues bien, para llevar a cabo esa determinación, la Constitución española de 1978, al proclamar que el fundamento «del orden político y de la paz social » reside, en primer término, en la «dignidad de la persona» y en «los derechos inviolables que le son inherentes» (art. 10.1) expresa una pretensión de legitimidad y, al propio tiempo, un criterio de validez que, por su propia naturaleza, resultan universalmente aplicables. Como hemos afirmado en varias ocasiones, "proyectada sobre los derechos individuales, la regla del art. 10.1 CE implica que, en cuanto 'valor espiritual y moral inherente a la persona' (STC 53/1985, de 11 de abril, FJ 8) la dignidad ha de permanecer inalterada cualquiera que sea la situación en que la persona se encuentre...constituyendo, en consecuencia un mínimum invulnerable que todo estatuto jurídico debe asegurar» [STC 120/1990, de 27 de junio, FJ 4; también STC 57/1994, de 28 de febrero, FJ 3 A)]. De modo que la Constitución española salvaguarda absolutamente aquellos derechos y aquellos contenidos de los derechos que «pertenecen a la persona en cuanto tal y no como ciudadanos o, dicho de otro modo...aquéllos que son imprescindibles para la garantía de la dignidad humana» (STC 242/1994, de 20 de julio, FJ 4; en el mismo sentido, SSTC 107/1984, de 23 de noviembre, FJ 2 y 99/1985, de 30 de septiembre, FJ 2)".

12 A dignidade da pessoa mencionada no artigo 10.1 da Constituição Espanhola "supõe o reconhecimento de um status especial da pessoa, que se situa por cima dos demais seres em virtude da sua racionalidade, que por sua vez determina a sua sociabilidade, liberdade, responsabilidade e dimensão trascendente". (ALEGRE MARTíNEZ, 1996, p. 17, tradução nossa). Para esse autor, "a racionalidade da pessoa determina que à sua dimensão corporal ou material apareçam inseparávelmente unidas às dimensões psíquica, moral e espiritual. Em virtude de todas elas, a pessoa na sua condição de tal, está revestida de uma especial dignidade". (ALEGRE MARTíNEZ, 1996, p. 17, tradução nossa).

13 O recurso de amparo é uma das principais competências do Tribunal Constitucional Espanhol, outorgada diretamente pela Constituição. O objetivo desta figura ou mecanismo é a proteção dos cidadãos contra violações dos direitos e liberdades reconhecidos pelos artigos 14 a 29 e artigo 30.2 da Constituição Espanhola, violações essas que podem ser causadas por disposições, atos jurídicos ou outros comportamentos por parte dos poderes públicos. Resumidamente, o recurso de amparo visa à proteção e à salvaguarda dos direitos e liberdades fundamentais.

14 Com base no que acabamos de referir, Gutiérrez Gutiérrez (2005, p. 91, tradução nossa) justifica a sua posição quanto à sua negativa em aceitar a dignidade como direito fundamental no constitucionalismo espanhol. Esclarece esse autor que, "a dignidade da pessoa, à margem da garantia reconhecida pelo art. 53.1 da Constituição, excluida do âmbito do recurso de amparo (art. 53.2 CE) e estranha inclusivamenta à proteção reforçada que brinda o art. $168 \mathrm{CE}$, não opera no nosso ordenamento como direito fundamental". 
Portanto, consideramos que, se fosse intenção inequívoca do legislador constitucional dotar a dignidade e o livre desenvolvimento da personalidade de um caráter ou natureza fundamental, assim o teria feito, concretamente incluindo-a no artigo 53, anteriormente citado. ${ }^{15}$

2) Em segundo lugar, apesar de ser considerado um valor superior do ordenamento jurídico ${ }^{16}$ e bem jurídico constitucionalmente protegido, ${ }^{17}$ essas qualidades não são suficientes para permitir ou possibilitar a criação de novos direitos. ${ }^{18}$ Pelo contrário, a dignidade e o livre desenvolvimento da personalidade estão indissociavelmente relacionados (e servirão de inspiração ou de fonte ${ }^{19}$ ) com diversos direitos inerentes à própria e estricta condição da pessoa ${ }^{20}$ (entendida como digna e merecedora de respeito pelos demais), como podem ser aqueles tutelados pelos artigos 14 (igualdade ante a lei), 15 (direito à vida e à integridade física e moral), 16 (liberdade ideológica, religiosa e de culto), 17 (liberdade e segurança) ou, no que diz respeito concretamente ao objeto de análise deste artigo, pelo art. 18 (sobre o direito à honra, intimidade, própria imagem e proteção de dados pessoais).

3) Como já abordamos anteriormente, a dignidade e o livre desenvolvimento da personalidade constituem um fundamento da ordem jurídico-social e dos direitos fundamentais constitucionalmente tutelados, ${ }^{21}$ possibilitando e permitindo a criação de novos direitos de acordo com as necessidades e exigências que reclame a sociedade em geral.

15 São várias as declarações do Tribunal Constitucional Espanhol nesse sentido. Assim, e a título de exemplo, a STC 57/1994, de 28 de Fevereiro, no seu Fundamento Jurídico $3^{\circ}$ justifica a não consideração da dignidade e o livre desenvolvimento da personalidade do art. 10.1 CE como direitos fundamentais da seguinte forma: "[...] no pueden servir de base para una pretensión autónoma de amparo por impedirlo los arts. 53.2 C.E. y 41.1 LOTC, que han configurado el recurso de amparo para la protección de los derechos y libertades reconocidos en los arts. 14 a 29 C.E. [...]. Ello sin perjuicio de que la regla del art. 10.1 C.E., proyectada sobre los derechos individuales, implica que la dignidad ha de permanecer inalterada cualquiera que sea la situación en que la persona se encuentre, constituyendo, en consecuencia, un mínimum invulnerable que todo estatuto jurídico debe asegurar, de modo que las limitaciones que se impongan en el disfrute de derechos individuales no conlleven un menosprecio para la estima que, en cuanto ser humano, merece la persona, aunque "sólo en la medida en que tales derechos sean tutelables en amparo y únicamente con el fin de comprobar si se han respetado las exigencias que, no en abstracto, sino en el concreto ámbito de cada uno de aquéllos, derivan de la dignidad de la persona, habrá que ser tomada en consideración por este Tribunal como referente". O que nesta instância declarou o Tribunal Constitucional não é mais que a confirmação do que já tinha ditado anteriormente, em concreto, na STC $120 / 1990$, de 27 de junho, que concluiu no seu Fundamento Jurídico $4^{\circ}$ que "De acuerdo com los arts. 53.2 C.E. y 41.1 LOTC, el recurso de amparo se ha configurado para la protección de los derechos y libertades reconocidos en los arts. 14 a 29 C.E., además de la objeción de conciencia a que se refiere el art. 30 , pero no para «la preservación de principios o normas constitucionales» (ATC 651/1985, fundamento jurídico $6^{\circ}$ ). Esta limitación objetiva del proceso de amparo permite a limine segregar, por ser ajenas al mismo, al menos tres de las nueve supuestas infracciones constitucionales que se denuncian en la demanda" para afirmar taxativamente, que "finalmente, otro tanto cabe decir en relación con la supuesta infracción, por violación de la dignidad de la persona, del art. 10.1 C.E. En efecto, que de acuerdo con este precepto, la dignidad de la persona y los derechos inviolables que le son inherentes sean, junto con el libre desarrollo de la personalidad, el respeto a la Ley y a los derechos de los demás, "fundamento del orden político y de la paz social», no significa ni que todo derecho le sea inherente -y por ello inviolable- ni que los que se califican de fundamentales sean in tolo condiciones imprescindibles para su efectiva incolumidad, de modo que de cualquier restricción que a su ejercicio se imponga devenga un estado de indignidad. Piénsese, precisamente, en la restricción de la libertad ambulatoria y conexas que padecen quienes son condenados a una pena privativa de libertad. Proyectada sobre los derechos individuales, la regla del art 10.1 C.E. implica que, en cuanto "valor espiritual y moral inherente a la persona» (STC 53/1985, fundamento jurídico $8^{\circ}$ ), la dignidad ha de permanecer inalterada cualquiera que sea la situación en que la persona se encuentre -también, qué duda cabe, durante el cumplimiento de una pena privativa de libertad, como repetidamente se cuida de señalar la legislación penitenciaria [arts. 3, 18, 20, 23, 26 b) LOGP; 3.1, 74.9, 80, 182 b), 230.1 RP]-, constituyendo, en consecuencia, un mínimum invulnerable que todo estatuto jurídico debe asegurar, de modo que, sean unas $u$ otras las limitaciones que se impongan en el disfrute de derechos individuales, no conlleven menosprecio para la estima que, en cuanto ser humano, merece la persona. Pero sólo en la medida en que tales derechos sean tutelares en amparo y únicamente con el fin de comprobar si se han respetado las exigencias que, no en abstracto, sino en el concreto ámbito de cada uno de aquéllos, deriven de la dignidad de la persona, habrá de ser ésta tomada en consideración por este Tribunal como referente. No, en cambio, de modo autónomo para estimar o desestimar las pretensiones de amparo que ante él se deduzcan". Esta posição vem a ser reforçada por outras decisões do Tribunal Constitucional, como podem ser os AATC 17/1995, de 24 de janeiro (FJ 1) e 149/1999, de 14 de junho (FJ 2), ou as Sentenças 136/1996, de 23 de julho (FJ 3) e 204/1997, de 25 de novembro, para as quais nos remetemos.

16 Entre outras, Sentenças 337/1994, de 23 de dezembro (FD 12: "[...] valor superior do ordenamento que se contêm no art. 10.1 C.E. como pórtico para os demais valores ou principios ali consagrados, o que revela a sua importancia fundamental"); $57 / 1994$, de 28 de fevereiro (cujo Fundamento Jurídico 3 A reproduzimos anteriormente); e, 120/1990, de 27 de julho, que também já foi abordada.

17 Que implica o respeito por parte dos poderes públicos como por parte dos próprios cidadãos (SSTC 53/1985, de 11 de abril -FJ8- e 91/2000, de 30 de março -FJ 7-.

18 Analisada minuciosamente esta problemática, pensamos que a dignidade e o livre desenvolvimento da personalidade serão objetivos que estão imersos em toda a regulação constitucional já que, sem a proteção do indivíduo, o Estado não existe. Por esse motivo, qualquer medida que se adote e que possa afetar os cidadãos terá sempre em consideração a dignidade e o livre desenvolvimento da personalidade como guias ou limites à atuação estatal

19 "La dignidad no es, como ya sabemos, un derecho propiamente dicho: es razón de ser de los derechos -que traen su causa de ella-, fin u objetivo de su reconocimiento constitucional, y límite de los mismos. En consonancia con ello, el artículo 10.1 es cabecera del Título I («De los derechos y deberes fundamentales»), pero sin formar parte de ninguno de los Capítulos que lo integran”. (ALEGRE MARTíNEZ, 1996, p. 118).

20 "[...] los derechos inviolables inherente a la persona en razón de su dignidad serán aquellos cuya vulneración atente contra la personalidad o contra su desarrollo". (ALEGRE MARTÍNEZ, 1996, p. 51).

21 Que, como já comprovamos, estão consagrados nos artigos 14 a 29 da Constituição Espanhola, e que vem a ser repetido pelo estabelecido no art. 53.2 do Texto Constitucional. 
No entanto, não podemos concordar com a capacidade que se pretende reconhecer à dignidade e ao livre desenvolvimento da personalidade na elaboração de novos mecanismos de defesa dos indivíduos, concreta e especificamente, na conceção e consagração de novos direitos fundamentais. Entendemos que, para que tal possa ocorrer, será preciso que se interprete um determinado e concreto direito fundamental, se analise o bem jurídico afetado que se pretende garantir, se ponderem os melhores meios de proteção dos indivíduos, para, a partir daí, apostar pela formulação de um novo direito de corte fundamental, ou extender o âmbito de atuação de um direito já existente e constitucionalmente tutelado. Esta última opção permitiria fazer convergir e incluir nessa esfera de proteção todas aquelas obrigações e necessidades que reclamem solução por parte do Direito e, consequentemente, a salvaguarda e amparo do bem jurídico afetado.

Ponderar a possibilidade de que a dignidade e o livre desenvolvimento da personalidade ${ }^{22}$ venham a viabilizar a elaboração de novos direitos seria abrir as portas a um perigoso precedente, especialmente no que se refere à consagração constitucional de direitos que, cada vez mais, se afastariam da lógica subjacente às funções e ideias político-legislativas. Reiteramos, dignidade e livre desenvolvimento da personalidade desempenham uma função de fundamento jurídico e social para a interpretação, aplicação e criação de outros direitos e bens jurídicos merecedores de amparo constitucional. Não obstante, não consideramos possível que, tanto o valor dignidade como o valor livre desenvolvimento da personalidade, sejam objeto de equiparação com os direitos fundamentais recolhidos e incluídos expressamente na Constituição. Caso contrário, e em situações extremas, tal poderia conduzir à desmesurada extensão do véu protetor do Direito e da própria Constituição, aceitando-se, inclusive, a construção de direitos potencialmente irrazoáveis e irracionais, justificado pelo simples fato de poder relacionar-se com a dignidade e o livre desenvolvimento da personalidade. Não será exagerado nem descabido, na nossa opinião, afirmar que essa "justificação" se pode alegar em quase qualquer circunstância e com respeito a quase todos -senão mesmo todos - os direitos que hipotéticamente se venham a ponderar.

4) Finalmente, e denunciando um pouco a nossa própria conclusão e posição sobre o tema objeto em análise, pensamos que, se o direito a ser esquecido - segundo Simón Castellano (2012) - tem por finalidade principal oferecer aos cidadãos um poder de controle sobre a sua informação pessoal ("poder escoger cuándo y dentro de qué límites procede revelar datos e informaciones que forman parte de su identidad"), então, aceitar a sua consagração constitucional fundamentada na dignidade e livre desenvolvimento da personalidade entraria em conflito direto com o disposto no art. 18.4 da Constituição Espanhola que, como bem sabemos, delimita o direito à proteção de dados pessoais. ${ }^{23}$

Para além do que acabamos de destacar, e repetindo o que já afirmamos, tanto no direito à intimidade como no próprio direito à proteção de dados pessoais, encontramos subjacente um fim partilhado e comum, isto é, a defesa, proteção e garantia da dignidade da pessoa, bem como o livre desenvolvimento da personalidade, já que esse controlo e domínio exercido sobre os dados e informações pessoais implica uma esfera de atuação livre de qualquer impedimento, barreira, obstáculo ou censura. Portanto, concluímos que "a dignidade humana aparece constitucionalmente traçada como um conjunto de direitos fundamentais integrado pelos direitos mais individuais e pessoalíssimos." (ENÉRIZ OLAECHEA, 2007, p.157, tradução nossa).

22 Pelo simples fato de existirem

23 Ou seja, no caso de que tal fosse possível, o conteúdo de um direito e de outro seríam desnecessariamente limitados (para além da confusão e incerteza jurídica que tal originaría), pois o direito à proteção de dados tem como objetivo ou finalidade última permitir aos indivíduos um controlo total sobre os seus dados e informações pessoais, constem em registos físicos ou em registos virtuais/digitais. Recordamos que o art. 18.4 da Constituição Espanhola determina que "a Lei limitará o uso da informática para garantir a honra e a intimidade pessoal e familiar dos cidadãos e o pleno exercício dos seus direitos”. (Tradução nossa). 


\subsection{Direito à intimidade ou direito à proteção de dados como fundamento do direito ao esquecimento? Posição adotada}

Excluída a terceira via sobre o fundamento e/ou natureza do direito ao esquecimento, ${ }^{24}$ é imprescindível determinar se esse fundamento ou natureza advém do direito à intimidade (com base no art. 18.1 CE) ou se, por outra parte, advém do direito à proteção de dados pessoais (art. 18.4 CE) a sua razão de ser. Do que não pode existir dúvida é que, independentemente da posição que se assuma e se defenda, o fim último ou objetivo principal de cada uma dessas posturas é a proteção dos indivíduos e dos seus dados pessoais, especialmente frente ao conhecimento não consentido, ou à difusão e divulgação nos meios digitais ou virtuais - Internet.

O artigo 18.1 da Constituição Espanhola pretende, com o direito ali definido e delimitado, salvaguardar a intimidade pessoal e familiar, ou seja, proteger o indivíduo de intromissões e ingerências não desejadas, e até ilegítimas, naqueles âmbitos da sua vida que se querem manter reservados: o direito à intimidade concede ao seu titular a faculdade de excluir terceiros do seu espaço íntimo e reservado; impossibilitando, dessa forma, que certas informações e dados pessoais sejam conhecidos ou publicitados. ${ }^{25}$

ASentença 292/2000, de 30 de novembro, enaltecida pelo esforço na definição do conceito e conteúdo do direito fundamental à proteção de dados pessoais, indicou que "a função do direito fundamental à intimidade do art. 18 CE é a de proteger frente a qualquer invasão que se possa realizar naquele âmbito da vida pessoal e familiar que a pessoa deseja excluir do conhecimento alheio e das intromissões de terceiros contra a sua vontade." ${ }^{26}$ (Tradução nossa).

Essa mesma decisão também demarcou as características que diferenciam o direito à intimidade pessoal e familiar do direito à proteção de dados pessoais, e que se podem resumir brevemente nas seguintes: a) em primeiro lugar, a função dos direitos: se o direito à intimidade visa salvaguardar esse espaço reservado e protegido de intromissões ilegítimas por parte de terceiros, assumindo, não obstante, uma atitude mais passiva; já o direito à proteção de dados concede ao indivíduo um conjunto de prerrogativas destinadas ao exercício de um total controlo sobre a sua informação pessoal; b) em segundo lugar, o objeto: se o artigo $18.1 \mathrm{CE}$ refere-se à intimidade constitucionalmente garantida e tutelada, o direito à proteção de dados amplia esse objeto tradicionalmente relacionado com o art. 18.1, de tal forma que se admite a inclusão de todo o tipo de dados e informações que digam respeito à pessoa (e já não apenas aquelas que se considerem "íntimas"27); e c) o conteúdo: se o direito à intimidade privada prevê a

24 Que, resumidamente, defende a consideração deste direito como autónomo e constitucionalmente garantido, motivado pela sua relação com a dignidade da pessoa e com o livre desenvolvimento da personalidade.

25 Neste sentido, é bastante clara a Sentença do Tribunal Constitucional Espanhol n ${ }^{\circ}$ 134/1999, de 15 de julho, cujo Fundamento Jurídico $5^{\circ}$ aborda esta questão. Assim, para o Tribunal Constitucional, "El derecho a la intimidad salvaguardado en el art. 18.1 C.E. tiene por objeto garantizar al individuo un ámbito reservado de su vida frente a la acción y al conocimiento de terceros, sean estos poderes públicos o simples particulares, que está ligado al respeto de su dignidad [...]. El derecho a la intimidad atribuye a su titular el poder de resguardar ese ámbito reservado por el individuo para sí y su familia de una publicidad no querida. El art. 18.1 C.E. no garantiza una «intimidad» determinada, sino el derecho a poseerla, a tener vida privada, disponiendo de un poder de control sobre la publicidad de la información relativa a la persona y su familia, con independencia del contenido de aquello que se desea mantener al abrigo del conocimiento público. Lo que el art. 18.1 garantiza es un derecho al secreto, a ser desconocido, a que los demás no sepan qué somos o lo que hacemos, vedando que terceros, sean particulares o poderes públicos, decidan cuáles sean los lindes de nuestra vida privada, pudiendo cada persona reservarse un espacio resguardado de la curiosidad ajena, sea cual sea el contenido de ese espacio. Del precepto constitucional se deduce que el derecho a la intimidad garantiza al individuo un poder jurídico sobre la información relativa a su persona o a la de su familia, pudiendo imponer a terceros su voluntad de no dar a conocer dicha información o prohibiendo su difusión no consentida, lo que ha de encontrar sus límites, como es obvio, en los restantes derechos fundamentales y bienes juridicos constitucionalmente protegidos".

26 Fundamento Jurídico $6^{\circ}$ da Sentença 292/2000, de 30 de novembro.

${ }_{27} \mathrm{O}$ mesmo Fundamento Jurídico $6^{\circ}$ da supracitada decisão afirma indiscutivelmente: "El derecho fundamental a la protección de datos amplia la garantía constitucional a aquellos de esos datos que sean relevantes para o tengan incidencia en el ejercicio de cualesquiera derechos de la persona, sean o no derechos constitucionales y sean o no relativos al honor, la ideología, la intimidad personal y familiar a cualquier otro bien constitucionalmente amparado. De este modo, el objeto de protección del derecho fundamental a la protección de datos no se reduce sólo a los datos íntimos de la persona, sino a cualquier tipo de dato personal, sea o no íntimo, cuyo conocimiento o empleo por terceros pueda afectar a sus derechos, sean o no fundamentales, porque su objeto no es sólo la intimidad individual, que para ello está la protección que el art. 18.1 CE otorga, sino los datos de carácter personal". Por nossa parte, entendemos que este é um exemplo expresso da teoria dos mosaicos, teoria sobre a qual assenta a proteção de dados pessoais. De acordo com esta teoria, existem dados e informações que, isoladamente considerados e conhecidos, nada significam, mas que relacionados e conectados uns com os outros, podem potencialmente permitir o conhecimento e elaboração de perfis muito completos e exatos sobre os indivíduos. Utiliza-se, para estes efeitos, a comparação com um mosaico: uma pedra solta num mosaico, nada representa. No entanto, se juntamos todas as peças e fragmentos do "puzzle", de forma ordenada, descobriremos finalmente o desenho ou a imagem completa do referido mosaico. 
possibilidade de que o interessado proíba a terceiros a ingerência na sua esfera íntima e reservada, bem como a divulgação e publicitação daquilo que possa vir a conhecer; o direito à proteção de dados, por outra parte, confere aos indivíduos um catálogo de "ferramentas" mais amplo e que consistem [...].

[...] em diversos poderes jurídicos cujo exercício impõe a terceiros deveres jurídicos, que não se contêm no direito fundamental à intimidade, e que servem à capital função que desempenha este direito fundamental: garantir à pessoa um poder de controlo sobre os seus dados pessoais, o que só é possível e efetivo impondo-se a terceiros os mencionados dever-fazer. ${ }^{28}$

Portanto, expostas novamente essas diferenças e tomando em consideração o objetivo defendido pelo direito ao esquecimento (latu sensu, a supressão de dados pessoais da Rede), consideramos que esse direito encontra uma base mais sólida e adequada no direito à proteção de dados pessoais, tal como aparece expresso no art. 18.4 da Constituição Espanhola.

Outra circunstância que nos leva a optar por considerar o direito fundamental à proteção de dados pessoais como fundamento do recentemente elaborado e consagrado direito ao esquecimento (desde a ótica da sua aplicação ao mundo virtual) são os meios mediante os quais os afetados e/ou interessados podem exercer o seu direito: falamos concretamento do direito de acesso, retificação, cancelamento e oposição.

Embora pese a eliminação e a supressão dos dados pessoais que circulam na Internet, que operam de forma distinta ao exercício destes direitos ARCO, não podemos negar que a finalidade de uns e de outros é a mesma, isto é, o controlo da informação pessoal por parte do seu titular. Se, por uma parte, a publicação de dados pessoais ${ }^{29}$ tem sido considerada como incluída dentro da noção geral de tratamento de dados pessoais, ${ }^{30}$ por outra parte, o direito de cancelamento viabiliza o bloqueio e supressão de uma informação constante num ficheiro quando esta seja desnecessária, não pertinente, errônea, incompleta ou inexata, para cumprir com o fim ou finalidade que motivou e justificou a sua obtenção. Finalmente, o direito de oposição implica a faculdade atribuída ao titular dos dados de opôr-se ao tratamento dessa mesma informação pessoal. ${ }^{31}$ Podemos sugerir, ainda que recorrendo-se à interpretação extensiva do conceito, que o direito ao esquecimento assenta a sua atuação e efeitos - em determinadas situações e respeitados concretos requisitos- nestas três circunstâncias e aspectos que acabamos de mencionar.

O direito ao esquecimento implicará, num primeiro momento, na oposição ao tratamento e à divulgação da informação (ao considerar-se que já não obedece à finalidade subjacente à sua recolha e

STC 292/2000, Fundamento Jurídico $6^{\circ}$.

E que, posteriormente, permitem o seu acesso e conhecimento por terceiros.

Implicando a sujeição à normativa comunitária em matéria de proteção de dados e, logo, à normativa nacional. Já a Sentença do Tribunal de Justiça da União Europeia, de 6 de novembro de 2003, C-101/01, Assunto Lindqvist, tinha declarado, no seu parágrafo 25, que "Quanto ao conceito de «tratamento» desses dados utilizados no artigo $3 .^{\circ},{ }^{\circ}{ }^{\circ} 1$, da Diretiva 95/46, ele abrange, de acordo com a definição do seu artigo $2 .^{\circ}$, alínea b), «qualquer operação ou conjunto de operações efetuadas sobre dados pessoais, com ou sem meios automatizados». Esta última disposição dá vários exemplos dessas operações, entre as quais figuram a comunicação por transmissão, a difusão ou qualquer outra forma de colocação à disposição de dados. Daqui resulta que a operação que consiste em fazer constar, numa página de Internet, dados de caráter pessoal consubstancia esse tratamento".

31 Sobre este tema, considera Rallo Lombarte (2018, p.183) que "el derecho al olvido admite su ejercicio a través de dos instrumentos jurídicos que, aunque de apariencia similar y resultado idéntico, tienen un alcance bien diferente en Internet y, en particular, ante la actividad de sus buscadores: el «derecho de cancelación» y el «derecho de oposición». El derecho de cancelación, previsto en el art. 16 LOPD dispone que el responsable del tratamiento tendrá la obligación de hacer efectivo el derecho de cancelación cuando el tratamiento de los datos no se ajuste a lo dispuesto en la presente Ley y, en particular, cuando tales datos resulten inexactos o incompletos, dando lugar a su bloqueo durante los plazos previstos en la legislación o los derivados de las relaciones contractuales. Como resulta evidente, proyectar genéricamente este derecho en Internet y, en particular, en la actividad de los motores de búsqueda resulta altamente conflictivo pues, la inexactitud, su carácter incompleto o la retirada o inexistencia de una autorización para el tratamiento de datos, comportaría una facultad habilitante para todo usuario que pondría ciertamente en cuestión la utilidad de los buscadores como herramientas esenciales de la sociedad de la información. Sin embargo, el derecho de oposición permite alcanzar idénticos objetivos (la supresión de datos personales indexados) pero por medios más acordes con el principio de proporcionalidad en la medida en que la supresión de datos requiere una ponderación individualizada de los motivos que pretenden justificarla y, por ende, no ampara una genérica habilitación de la supresión de información en Internet. Y ello es así por cuanto el art. 6.4 LOPD prevé que, en los casos en los que no sea necesario el consentimiento del afectado para el tratamiento de los datos de carácter personal, y siempre que una Ley no disponga lo contrario, éste podrá oponerse a su tratamiento cuando existan motivos fundados y legítimos relativos a una concreta situación personal". 
tratamento) e, num momento posterior, conduzirá a que essa mesma informação seja cancelada, ${ }^{32}$ isto é, que deixe de ser tratada, divulgada e difundida. Além disso, julgamos que esse novo direito pretende dar um passo mais em direção à real e efetiva proteção de dados por meio dum crescente aumento do poder de controle que se exerce sobre as suas informações pessoais: ao implicar a "destruição"33 da informação, eliminando-se qualquer possibilidade de recuperar e divulgar novamente esses dados, algumas vozes críticas acusaram os distintos legisladores de legitimarem um tipo de censura digital. ${ }^{34}$

Contudo, não se pode esquecer que os potenciais perigos para os indivíduos derivados da ilícita, ilegítima, abusiva, extemporânea, injustificada, desfasada (no tempo) utilização e divulgação dos dados pessoais, ${ }^{35}$ leva a que se procure que o direito ao esquecimento, sempre e quando seja exercido corretamente, finalize com a quase total impossibilidade de que se aceda ou divulgue novamente a informação que se quis "esquecer". ${ }^{36}$

Ainda sobre a natureza ou fundamento normativo do direito ao esquecimento, consideramos interessante a postura assumida e defendida por Gomes de Andrade (2012).

Para o autor, esse novo direito ao esquecimento encontra a sua justificação e fundamento jurídico no direito à identidade, e que o define como "o direito a que os sinais, os atributos ou as facetas da personalidade que são características duma pessoa em particular (como a aparência, o nome, o caráter, a voz ou a história da sua vida) sejam reconhecidos e respeitados pelos demais." (GOMES DE ANDRADE, 2012, p. 70-71, tradução nossa). Esta identidade não está paralizada, não é constante e inalterável, muito pelo contrário. A identidade é um aspeto do ser humano que é mutável, que evolui e que se adapta às novas circunstâncias e exigências, situações, realidades e conhecimentos. Para Gomes de Andrade (2012, p. 74), citando a Pino, a quem acompanha nessa observação,

[...] a identidade é mais um bem de construção cultural e social, algo que escolhemos, construimos e respeitamos. A identidade pessoal deve-se perceber como uma questão de opções, um processo de negociação contínua (conosco mesmos e com os demais), não predeterminada e unívoca, senão que se pode rever e modificar constantemente.

Julgamos que o objetivo do autor é ressaltar a ideia de que a pessoa que fomos ontem não é necessariamente a pessoa que somos hoje ou que seremos amanhã. As nossas opções e as nossas opiniões não são lineares. A nossa forma de ser e de pensar não se mantém intacta ao longo do tempo, sendo natural e provável que, a qualquer momento, o ser humano se arrependa de alguma opção que

32 Ainda que consciente das dificuldades que tal pode comportar, López Portas encontra uma semelhança entre o direito ao esquecimento e o direito de cancelamento no âmbito do ordenamento jurídico espanhol. Dito isto, e segundo a opinião de López Portas (2015, p.151, tradução nossa): "A universalidade da informação, a potencial interceção das comunicações e os riscos de acesso, difusão ou alteração dos dados por parte de terceiros são uma constante preocupação para a normativa espanhola. Numa primeira tentativa para evitar a publicação em Internet da informação privada, atende-se à regulação dos direitos de acesso, retificação e cancelamento dos dados privados que constassem em bases públicas ou privadas. De maneira que o direito ao esquecimento coincide assim com o direito de cancelamento de dados. Uma equiparação que apresenta certos inconvenientes, sobretudo no que se refere ao cancelamento ou retificação de bases de dados oficiais -ao serem estas excluídas da regulação geral- no que se refere ao problema dos antigos dados difundidos ou publicados em diários ou jornais digitais, ou a dificuldade que implica a aplicabilidade da normativa nacional a empresas e servidores de Internet localizados fora das fronteiras europeias".

33 Dizemos destruição em um sentido figurado, pois a informação não desaparece nem é eliminada por completo. O que acontece nestas situações é que o acesso à informação e a possível difusão (e o potencial efeito multiplicador dos motores de busca, como é Google) se dificulta ao máximo, limitando-se, dessa forma, as agressões ao direito à proteção de dados pessoais.

34 Especialmente críticos foram os argumentos apresentados pelos motores de busca (Google, por exemplo) nos vários pleitos que foram objeto de apreciação por parte dos tribunais espanhóis. Os perigos ou inconvenientes da regulação do direito ao esquecimento foram resumidos por S. Abril e por Pizarro Moreno (2014, p.12), entre os quais, destacaram uma forma de censura subtil. Nesse sentido, afirmam que: "Se trata también de uno de los argumentos más argüidos contra el establecimiento del derecho al olvido: al permitir a las personas eliminar a voluntad los datos que le afecten, la información relevante puede llegar a ser incompleta, inaccesible o erróneamente representativa de la realidad. Es decir, y como veremos con detenimiento, el establecimiento de este derecho podría suponer una fricción insalvable con las libertades de expresión e información. En definitiva, podría abrir una puerta a otras formas de censura".

35 Principalmente se considerarmos a facilidade e a rapidez com que a informação se transmite na Internet.

36 Como se sabe, e tal como abordamos anteriormente, com o real e efetivo exercício do direito ao esquecimento a informação não desaparecerá por completo do mundo virtual (Internet): o que sim, se comprovará, é que o acesso a essa mesma informação se dificultará através, por exemplo, da sua desindexação, pelo que, consequentemente, deixará de aparecer na lista de resultados dos motores de busca, como é o Google. 
tenha tomado, ou que assuma que uma opinião pessoal passada estava equivocada. Logo, é razoável e plausível que o afectado requeira que essa circunstância não o afete (no presente ou, inclusivamente, no futuro), justificando-se dessa forma o exercício do direito ao esquecimento. Nesse sentido, conclui o autor que

[...] el derecho al olvido no solo se debe considerar desde el punto de vista de la privacidad, sino también desde el de la identidad. Por tanto, es importante reconocer no solo las consecuencias inmediatas de la aplicación del derecho a ser olvidado, es decir, la posibilidad de ocultar una serie de hechos y acciones pasadas del conocimiento público (la perspectiva de la privacidad), sino también tener en cuenta las implicaciones más profundas de la aplicación de tal derecho, es decir, lo que el derecho al olvido nos permite hacer después. [...] El derecho al olvido constituye el derecho a ser diferente no solo de los demás, sino de uno mismo, del individuo que fuimos en el pasado. El derecho al olvido, como tal, pone de relieve el proceso de deconstrucción de la identidad por el que se pueden eliminar viejas identidades y se pueden formar otras nuevas. Además, el derecho a ser olvidado también equivale al derecho a un nuevo comienzo, el derecho a empezar de nuevo desde cero y el derecho a la autodefinición, que evita que el pasado condicione (de una manera excesiva) nuestra vida presente y futura. (GOMES DE ANDRADE, 2012, p. 80).

\section{Conclusão}

Ao longo das últimas páginas, foi nosso objetivo abordar e explicar as três principais teorias em torna do direito ao esquecimento.

Dessa forma, e por tudo o que foi exposto, julgamos que, considerar o direito ao esquecimento como uma consequência direta e necessária do direito fundamental à proteção de dados de caráter pessoal é a opção mais acorde com a sua própria natureza e com a sua própria finalidade, isto é, reforçar os mecanismos, ou prerrogativas, atribuídas aos cidadãos para o real e efetivo controlo sobre as suas informações, especialmente sobre aquelas que circulam na Internet.

Além do mais, as garantias que se lhe oferecem são significativamente maiores.

Por um lado, devido à sua vinculação com um direito fundamental e constitucionalmente tutelado (como é o direito à proteção de dados de caráter pessoal definido no artigo 18.4 da Constituição Espanhola), e com base no bem jurídico que se pretende salvaguardar, estará protegido pelos meios, ações, direitos e procedimentos especificamente regulados para a defesa desse tipo de direito (constitucionais). É o caso do recurso de amparo a que nos referimos, e que se encontra consagrado pelo artigo 53.2 da CE.

Por outro lado, consente-se e concede-se uma proteção administrativa específica, que atua mediante a apresentação duma reclamação ante um órgão público independente e autoridade de controlo e fiscalização, como é a Agência Espanhola de Proteção de Dados (cujas funções e poderes sancionadores encontram-se descritas nos artigos 35 e seguintes da Lei Espanhola de Proteção de Dados, e nos artigos 115 e seguintes do Regulamento que vem a desenvolver as matérias legisladas na LOPD). Essa agência é a que, no território espanhol, zela pelo cumprimento da normativa de proteção de dados por todos os intervenientes, sejam eles públicos, sejam privados; e que, a posteriori, pode e deve garantir que o direito à proteção da informação pessoal (e, como é óbvio, o direito ao esquecimento) seja respeitado, sancionando qualquer conduta que limite ou restrinja de forma ilícita o exercício desta faculdade por parte dos afetados.

\section{Referências}

ALEGRE MARTÍNEZ, Miguel Ángel. La dignidad de la persona como fundamento del ordenamiento constitucional español. León: Universidad de León, 1996.

DE ESTEBAN, Jorge; GONZÁLEZ-TREVIJANO, Pedro J. Curso de derecho constitucional español II. Primera Edición 1993. Reimpresión 1997. Madrid: Universidad Complutense de Madrid, 1997. 
ENÉRIZ OLAECHEA, Francisco Javier. La protección de los derechos fundamentales y las libertades públicas en la Constitución Española. Pamplona: Universidad Pública de Navarra, 2007.

GOMES DE ANDRADE, Norberto Nuno. El olvido: El derecho a ser diferente... de uno mismo. Una reconsideración del derecho a ser olvidado. Revista de Internet, Derecho y Política, Catalunya, n. 13, 2012. [Monográfico "VII Congreso Internacional Internet, Derecho y Política. Neutralidad de la red y otros retos para el futuro de Internet". Universitat Oberta de Catalunya].

GUTIÉRREZ GUTIÉRREZ, Ignacio. Dignidad de la persona y derechos fundamentales. Madrid: Marcial Pons, 2005.

LÓPEZ PORTAS, María Begoña: La configuración jurídica del derecho al olvido en el Derecho español a tenor de la doctrina del TJUE. UNED: Revista de Derecho Político, Madrid, n. 93, mayo/agosto 2015.

MIERES MIERES, Luis Javier: "EI derecho al olvido digital". Documento de trabajo 186/2014, Laboratorio de Alternativas. Madrid: Fundación Alternativas, Junio 2014.

RALLO LOMBARTE, Artemi. El derecho al olvido en el tiempo de Internet: la experiencia española. Disponible en: <repositori.uji.es/xmlui/handle/10234/122643>. Acesso en: 12 enero 2018.

SÁNCHEZ ABRIL, Patricia; PIZARRO MORENO, Eugenio. La intimidad europea frente a la privacidad americana. Una visión comparativa del derecho al olvido. Revista para el análisis del Derecho, Barcelona, n. 1, Universidad Pompeu Fabra, p. 12, 2014. Disponible en: <http://www.indret.com/ pdf/1031.pdf> Acesso en: 26 fev. 2018.

SIMÓN CASTELLANO, Pere. El régimen constitucional del derecho al olvido digital. Valencia: Tirant lo Blanch, 2012.

VON MÜNCH, Ingo. La dignidad del hombre en el Derecho Constitucional. Traducción por Jaime Nicolás Muñiz. Revista Española de Derecho Constitucional, Madrid, ano 2, n. 5, mayo-agosto, 1982.

Recebido em: 02/03/2018

Aprovado em: 16/03/2018 